\title{
Endogenous prolactin-releasing peptide regulates food intake in rodents
}

\author{
Yuki Takayanagi, ${ }^{1}$ Hirokazu Matsumoto, ${ }^{2}$ Masanori Nakata, ${ }^{3}$ Takashi Mera, ${ }^{4}$ Shoji Fukusumi, ${ }^{5}$ \\ Shuji Hinuma, ${ }^{5}$ Yoichi Ueta,, ${ }^{4}$ Toshihiko Yada, ${ }^{3}$ Gareth Leng, ${ }^{6}$ and Tatsushi Onaka ${ }^{1}$ \\ 1Division of Brain and Neurophysiology, Department of Physiology, Jichi Medical University, Shimotsuke, Tochigi, Japan. \\ 2Frontier Research Laboratories I, Pharmaceutical Research Division, Takeda Chemical Industries Ltd., Tsukuba, Ibaraki, Japan. \\ ${ }^{3}$ Division of Integrative Physiology, Department of Physiology, Jichi Medical University, Shimotsuke, Tochigi, Japan. \\ ${ }^{4}$ Department of Physiology, University of Occupational and Environmental Health, Kitakyushu, Japan. \\ ${ }^{5}$ Research Information \& Alliances Strategic Research Planning Department, Pharmaceutical Research Division, Takeda Chemical Industries Ltd., \\ Juso-honmachi, Yodogawaku, Osaka, Japan. ${ }^{6}$ Centre for Integrative Physiology, School of Biomedical Sciences,
} University of Edinburgh, Edinburgh, United Kingdom.

\begin{abstract}
Food intake is regulated by a network of signals that emanate from the gut and the brainstem. The peripheral satiety signal cholecystokinin is released from the gut following food intake and acts on fibers of the vagus nerve, which project to the brainstem and activate neurons that modulate both gastrointestinal function and appetite. In this study, we found that neurons in the nucleus tractus solitarii of the brainstem that express prolactin-releasing peptide (PrRP) are activated rapidly by food ingestion. To further examine the role of this peptide in the control of food intake and energy metabolism, we generated PrRP-deficient mice and found that they displayed late-onset obesity and adiposity, phenotypes that reflected an increase in meal size, hyperphagia, and attenuated responses to the anorexigenic signals cholecystokinin and leptin. Hypothalamic expression of 6 other appetite-regulating peptides remained unchanged in the PrRP-deficient mice. Blockade of endogenous PrRP signaling in WT rats by central injection of PrRP-specific $m A b$ resulted in an increase in food intake, as reflected by an increase in meal size. These data suggest that PrRP relays satiety signals within the brain and that selective disturbance of this system can result in obesity and associated metabolic disorders.
\end{abstract}

\section{Introduction}

Classically, feeding is regulated by an alternation between hunger and satiety signals, which include both circulating factors and neurally mediated signals from the gastrointestinal tract (1). These signals act on the peripheral organs and on the CNS, including the hypothalamus and brainstem, to initiate or terminate food intake. One important satiety signal is the brain-gut peptide cholecystokinin (CCK). CCK, released from the gut in response to a meal, has an important regulatory role in gastrointestinal function, inhibiting gastric motility and emptying via a neural reflex within the caudal brainstem or via a reflex loop that ascends to the hypothalamus via a relay in the caudal brainstem $(2,3)$, but is also involved in the regulation of food intake. Peripheral CCK acts on afferent nerve fibers of the gastric vagus nerve; these vagal neurons project to the caudal brainstem (4), where they activate neurons that project to hypothalamic nuclei involved in appetite regulation $(2,3)$. In particular, peripheral injections of CCK activate neurons in the nucleus tractus solitarii (NTS) and ventrolateral medulla, including specific subpopulations of the noradrenergic neurons of the A1 and A2 cell groups (5). These noradrenergic neurons comprise several subpopulations, which are anatomically, biochemically, and functionally separate.

Nonstandard abbreviations used: AgRP, agouti-related protein; BAT, brown adipose tissue; CART, cocaine- and amphetamine-regulated transcript; CCK, cholecystokinin; $\mathrm{CRH}$, corticotrophin-releasing hormone; i.c.v., intracerebroventricular(ly); NPY, neuropeptide Y; NTS, nucleus tractus solitarii; $\mathrm{p}$-CREB, phosphorylated cAMP response element-binding protein; POMC, proopiomelanocortin; PrRP, prolactinreleasing peptide; $\mathrm{UCP} 1$, uncoupling protein $1 ; \mathrm{VO}_{2}$, oxygen consumption.

Conflict of interest: Hirokazu Matsumoto, Shoji Fukusumi, and Shuji Hinuma are employees of Takeda Chemical Industries Ltd.

Citation for this article: J. Clin. Invest. doi:10.1172/JCI34682.
Some of these noradrenergic neurons express prolactin-releasing peptide (PrRP; encoded by the Prlh gene) (6). PrRP was discovered as an endogenous ligand for the GPCR GPR10 (encoded by the Prlbr gene) (7), and PrRP-expressing neurons are localized in the NTS and ventrolateral medulla oblongata and in the dorsomedial hypothalamus $(8,9)$. In the medulla oblongata, PrRP is exclusively colocalized in noradrenergic neurons (6). PrRP has been suggested to be involved in energy metabolism (10-15), stress responses (16-19), and analgesia (20).

Peripheral administration of CCK activates neurons expressing PrRP (11). There have also been several other indications that PrRP might be involved in the regulation of feeding and energy balance. In particular, central administration of PrRP reduces food intake in rats (10), and PrRP mRNA expression decreases during fasting and is low during lactation, a physiological state of negative energy balance (10). Mice that lack the PrRP receptor GPR10 show adultonset obesity $(15,21)$ and, most interestingly, do not reduce their feeding in response to CCK (22).

Here, we examined the role of endogenous PrRP in the control of food intake and energy metabolism by studies in $\mathrm{Tg}$ mice deficient in PrRP and by neutralizing the actions of endogenous PrRP in mice and rats using $\mathrm{mAb}$ specific for PrRP. We also investigated whether food intake activates PrRP neurons in the caudal brainstem. In this study, we demonstrate that in rodents, PrRP relays satiety signals within the brain and that perturbation of this system can predispose to obesity and associated metabolic disorders.

\section{Results}

Generation of PrRP-deficient mice. To generate mice deficient in PrRP, we designed a targeting vector to disrupt exons 1 and 2 including full coding regions of the prepro-PrRP sequence (Figure 1A). Male 
A

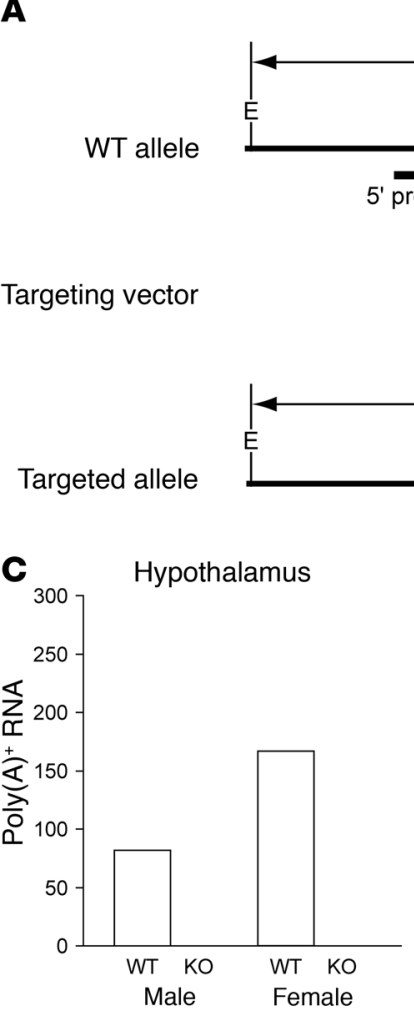

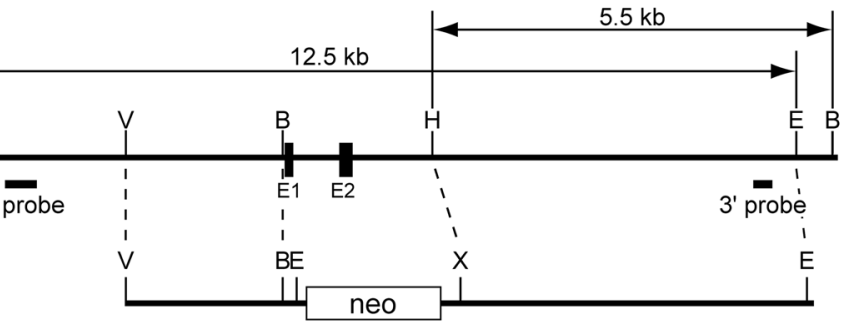

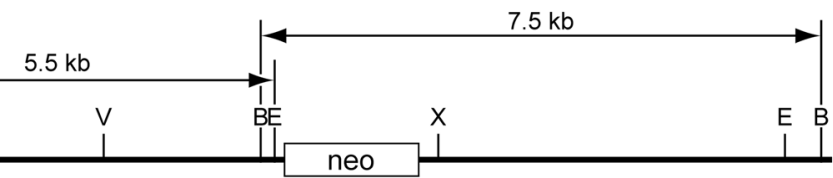

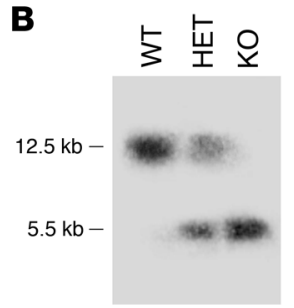
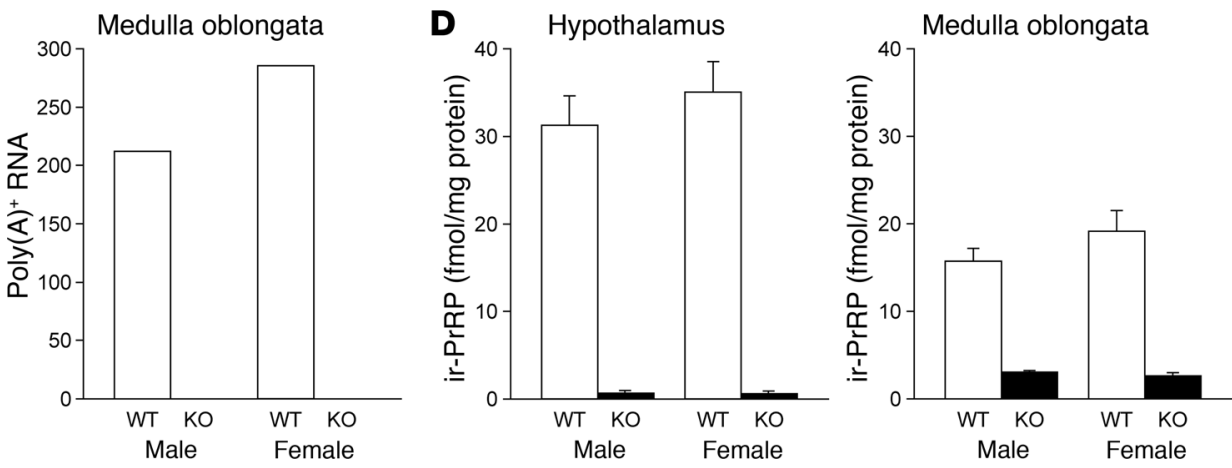

Figure 1

Generation of PrRP-deficient mice. (A) Genomic structure of the murine Prlh gene and the targeting vector; and predicted genomic structure of the targeted allele. Exons (E1, E2) are indicated by black boxes. Positions of restriction enzyme sites and the probes used for Southern blot analysis are shown. E, EcoRI; V, Vspl; B, BamHI; H, Hpal; X, Xhol; neo, neomycin phosphotransferase resistance cassette. (B) Southern blot analysis of tail genomic DNA isolated from WT, PrRP-heterozygous (HET), and PrRP-deficient (KO) mice. DNA was digested with EcoRI and hybridized with a $5^{\prime}$ probe. WT allele and targeted allele correspond to the 12.5-kb and 5.5-kb fragments. Southern blot analysis with a $3^{\prime}$ probe also confirmed that the Prlh locus was properly targeted (data not shown). Quantitative RT-PCR analysis (C) and radioimmunoassay (D) confirmed the absence of PrRP transcripts and proteins in the hypothalamus and medulla oblongata of PrRP-deficient mouse. Error bars indicate SEM. ir, immunoreactive.

chimeric mice transmitted the mutant Prlh allele to their offspring. The heterozygous mice were apparently normal and were intercrossed to obtain homozygous offspring; these mice were viable (Figure 1B). PrRP transcripts and proteins were not detectable in PrRP-deficient mice, confirming the disruption of the Prlb gene (Figure 1, C and D).

Adult-onset obesity in PrRP-deficient mice. When WT, PrRP-heterozygous, and PrRP-deficient mice from heterozygous intercrosses were fed a high-fat diet ad libitum from the age of 5 weeks, PrRPdeficient mice became significantly heavier than either WT mice or PrRP-heterozygous mice by the age of 7 weeks (Figure 2A). When maintained on standard laboratory chow, PrRP-deficient mice weighed significantly more than WT mice at 18 weeks of age (Figure 2B), which was apparently attributable to greater food consumption (Figure 2C). PrRP-deficient mice had substantially more body fat than WT mice (Figure 2D), and this was accompanied by reduced glucose tolerance and increased insulin resistance (Figure 2, E and F). Both WAT mass, in either subcutaneous pads or intraabdominal pads (perirenal, mesenteric, epididymal), and brown adipose tissue (BAT) mass were greater in PrRP-deficient mice than in WT mice (Figure $2 \mathrm{G}$ ), and epididymal adipocytes of PrRP-deficient mice were larger than those in WT mice
(Figure 2H). The hepatic tissue of PrRP-deficient mice contained many large fatty vesicles, indicating fatty liver (Figure $2 \mathrm{H}$ ). Plasma concentrations of insulin, leptin, and triglyceride were higher in PrRP-deficient than in WT mice (insulin: WT, $850 \pm 191 \mathrm{pg} / \mathrm{ml}$, PrRP-deficient, 3,001 $\pm 672 \mathrm{pg} / \mathrm{ml}$; leptin: WT, $11.5 \pm 5.9 \mathrm{ng} / \mathrm{ml}$, PrRP-deficient, $40.3 \pm 12.9 \mathrm{ng} / \mathrm{ml}$; triglyceride: WT, $71.2 \pm 3.5 \mathrm{ng} / \mathrm{dl}$, PrRP-deficient, $95.5 \pm 5.7 \mathrm{ng} / \mathrm{dl}$ ). Hepatic triglyceride concentrations were also higher in PrRP-deficient mice than in WT mice $(1.23 \pm 0.25$ vs. $0.27 \pm 0.04 \mathrm{mg} / \mathrm{mg}$ protein $)$. The greater $\mathrm{BW}$ gain of PrRP-deficient mice was more prominent when they were fed a high-fat diet (Figure 3A), and this was associated with a significantly greater food intake (Figure 3B).

Energy expenditure in PrRP-deficient mice. To examine the pathogenesis of obesity in PrRP-deficient mice, amounts of food supplied were restricted to the mean food intake of age-matched WT mice. Under these conditions, the BWs of pair-fed PrRP-deficient mice did not differ significantly from those of WT mice (Figure $3 \mathrm{C}$ ). Glucose tolerance and insulin resistance were also not significantly different in WT and pair-fed PrRP-deficient mice (Figure 3, D and E).

We found no significant differences between WT and PrRP-deficient mice in locomotor activity in their home cages (Figure 4A) 


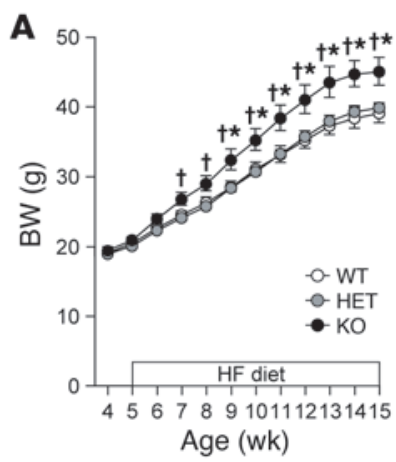

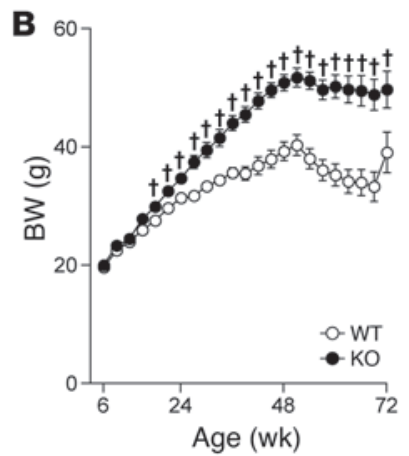
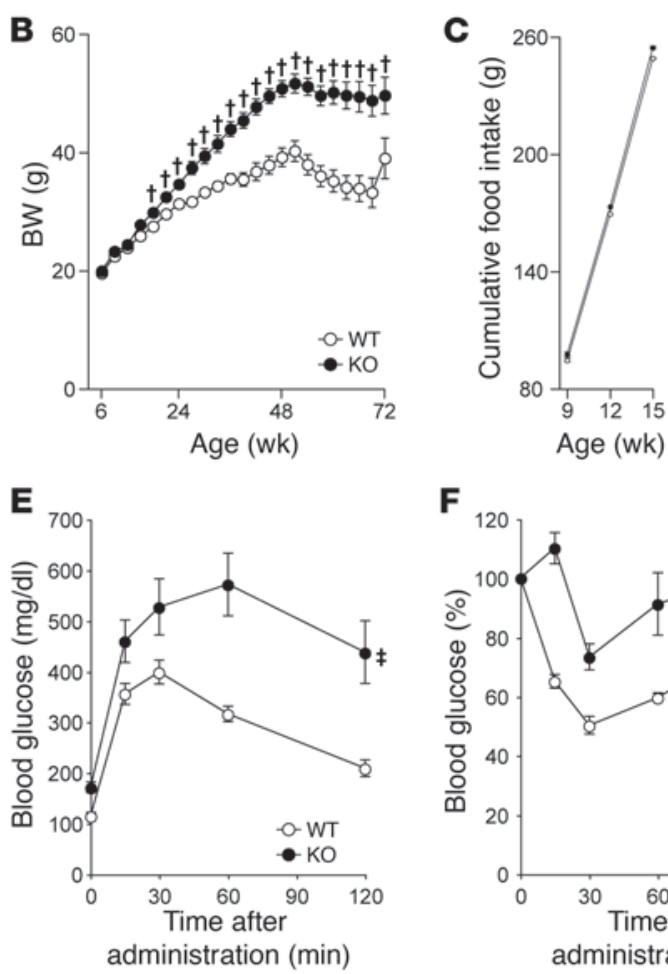

administration (min)

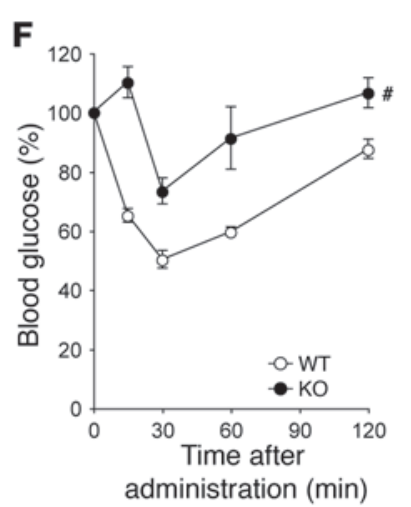

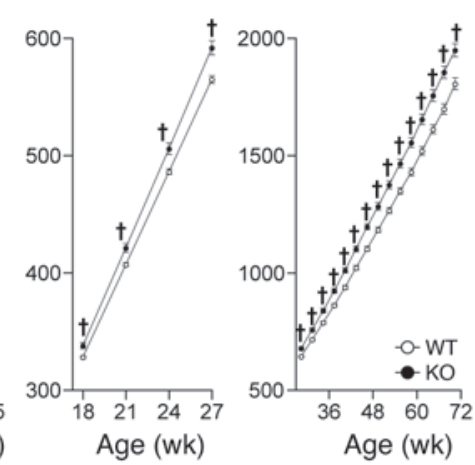

G

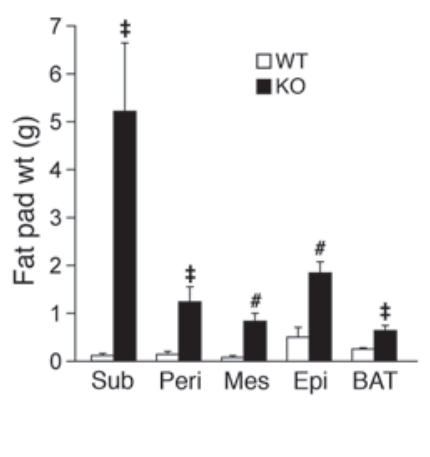

$\mathbf{H}$

WT

$\mathrm{KO}$

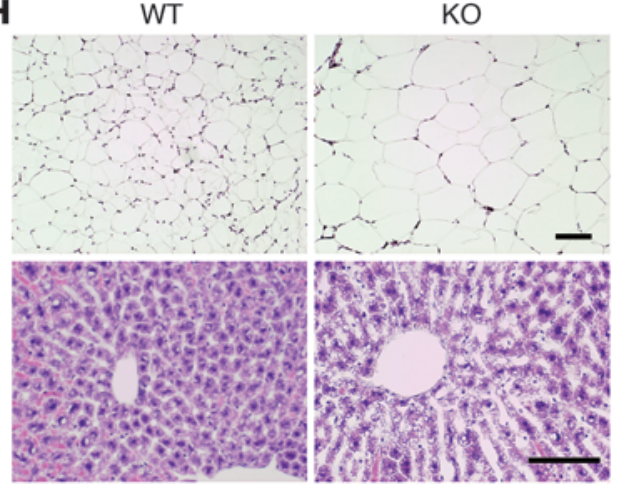

Figure 2

Late-onset obesity in PrRP-deficient mice. (A) Mean BWs of WT, PrRP-heterozygous, and PrRP-deficient mice from heterozygous intercrosses, fed a high-fat diet (HF) from the age of 5 weeks. Under the high-fat diet condition, PrRP-deficient mice became heavier than WT and PrRPheterozygous mice from the age of 7 weeks $(n=6$ or 7$)$. Mean BWs (B) and cumulative food intake (C) of WT and PrRP-deficient mice at the ages of 6-72 weeks. PrRP-deficient mice older than 18 weeks were heavier and ate more than WT mice $(n=6)$. (D) At 66 weeks of age, PrRPdeficient mice were markedly fatter than WT mice. Scale bar: $5 \mathrm{~cm}$. (E) At the age of 39-40 weeks, PrRP-deficient mice fed standard laboratory chow showed reduced glucose tolerance compared with WT mice $(n=5$ or 6$)$. (F) Insulin resistance tests at the age of 40-41 weeks showed that PrRP-deficient mice also had increased insulin resistance. (Blood glucose concentrations before insulin administration were set as $100 \%$; $n=5$ or 6.) (G) Mean weight of fat pads of subcutaneous region (Sub), perirenal region (Peri), mesenteric region (Mes), epididymal region (Epi), and BAT. At the age of 72 weeks, PrRP-deficient mice had much larger fat masses than WT mice $(n=6)$. (H) WAT (upper panel) and liver (lower panel) of WT and PrRP-deficient mice at the age of 72 weeks (H\&E staining). Scale bars: $100 \mu \mathrm{m}$. Error bars indicate SEM. ${ }^{\dagger} P<0.05, \ddagger P<0.01$, ${ }^{\#} P<0.001$ versus WT mice; ${ }^{*} P<0.05$ versus PrRP-heterozygous mice.

and no significant differences in oxygen consumption $\left(\mathrm{VO}_{2}\right)$ during 12-hour dark, 12-hour light, and 24-hour periods for mice at the ages of 9,16 , and 51 weeks (Figure 4B). The mean respiratory exchange ratios were also not significantly different in WT and PrRP-deficient mice at the age of 9 (WT, $0.92 \pm 0.01$, PrRP-deficient, $0.92 \pm 0.01$ ), 16 (WT, $0.91 \pm 0.01$, PrRP-deficient, $0.88 \pm 0.01$ ), or 51 weeks (WT, $0.81 \pm 0.02$, PrRP-deficient, $0.84 \pm 0.01$ ). In pairfed PrRP-deficient mice at the age of 52-54 weeks, neither the total
$V \mathrm{O}_{2}$ nor the mean respiratory exchange ratios were significantly different from those in WT mice (Table 1).

We then examined $\mathrm{VO}_{2}$ in animals whose endogenous PrRP functions were acutely blocked by neutralizing PrRP mAb. We found no significant differences between control animals and animals pretreated with anti-PrRP mAb (Figure 4C).

Uncoupling proteins are involved in the regulation of thermogenesis and energy expenditure through the sympathetic 

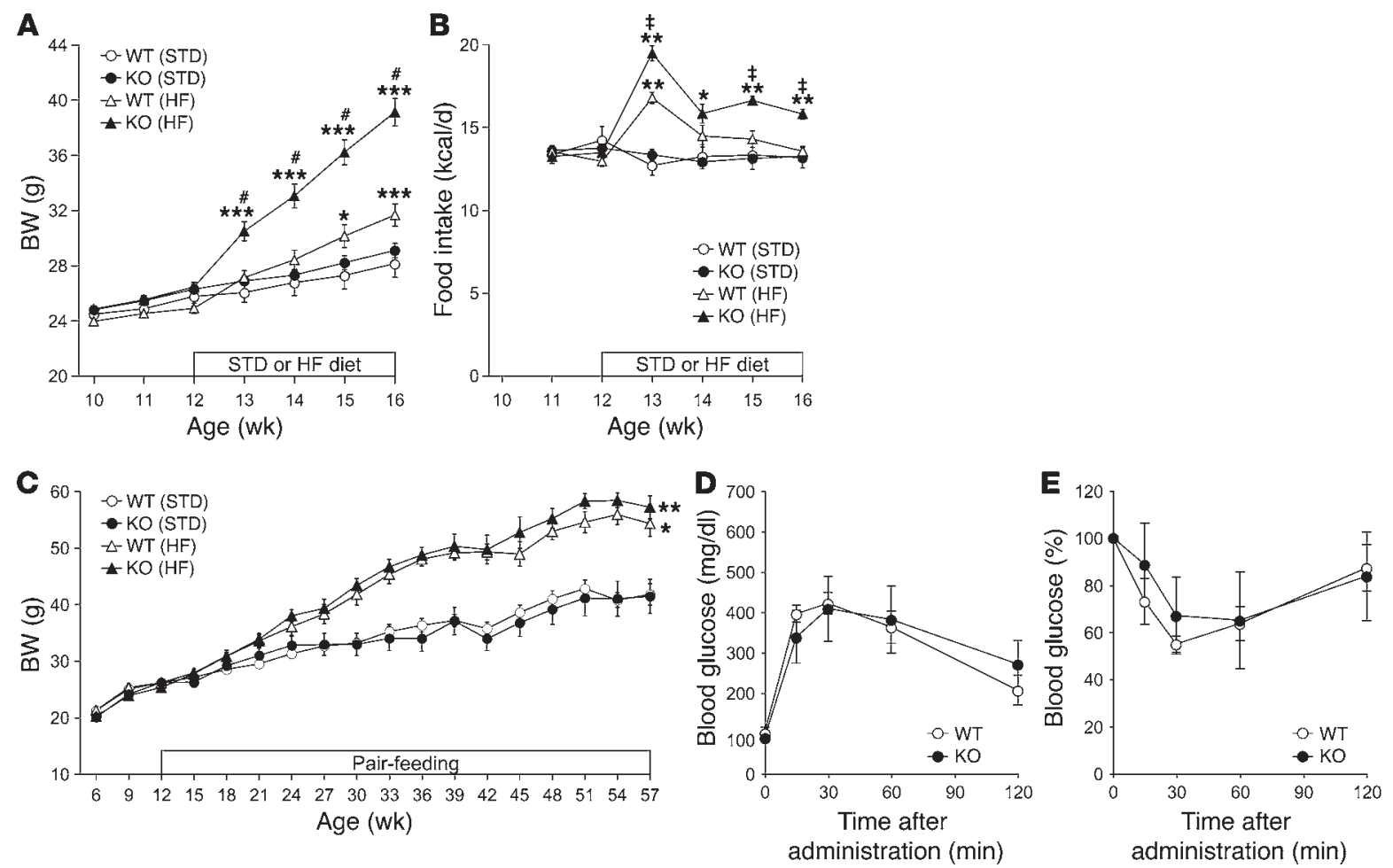

Figure 3

Energy utilization in PrRP-deficient and WT mice. BW (A) and food intake (B) of mice fed standard laboratory chow (STD) or high-fat diet from the age of 12 weeks (at the ages of 10-16 weeks, PrRP-deficient mice fed standard laboratory chow had not yet begun to show obesity). Mice fed a high-fat diet gained BW faster, with a significantly greater gain in PrRP-deficient mice. Food intake was greater in PrRP-deficient mice at ages when they were heavier than WT mice $(n=4)$. (C) BWs of WT and pair-fed PrRP-deficient mice from 6 to 57 weeks of age. Half of the mice were fed standard laboratory chow or high-fat diet from the age of 12 weeks. The BWs of pair-fed PrRP-deficient mice were not significantly different from those of WT mice ( $n=6$ or 7). (D) At the age of 39-40 weeks, pair-fed PrRP-deficient mice on standard laboratory chow had glucose tolerance similar to that of WT mice $(n=6$ or 7$)$. (E) At the age of 40-41 weeks, pair-fed PrRP-deficient mice on standard laboratory chow showed insulin resistance similar to that of WT mice. (Blood glucose concentrations before insulin administration were set as $100 \%$; $n=6$ or 7 .) Error bars indicate SEM. ${ }^{\prime} P<0.01,{ }^{\sharp} P<0.001$ versus WT mice; ${ }^{*} P<0.05$, ${ }^{* *} P<0.01$, ${ }^{\star *} P<0.001$ versus mice fed standard chow.

nervous system. Therefore, we examined body temperature and uncoupling protein 1 (UCP1) mRNA expression in the BAT after exposure to cold. There was no significant difference in core body temperature between WT and PrRP-deficient mice either before $\left(37.5 \pm 0.1^{\circ} \mathrm{C}\right.$ and $37.5 \pm 0.1^{\circ} \mathrm{C}$, respectively) or after $(37.3 \pm 0.1$ and $37.2^{\circ} \mathrm{C} \pm 0.2^{\circ} \mathrm{C}$, respectively) exposure to cold. Expression of UCP1 mRNA in the BAT was increased after exposure to cold, but with no significant difference between WT and PrRP-deficient mice (Figure 4D).

Collectively, these data indicate that the obesity in PrRPdeficient mice mainly reflects hyperphagia rather than lower energy consumption.

Activation of PrRP neurons by food intake. We examined the expression of phosphorylated cAMP response elementbinding protein ( $\mathrm{p}$-CREB) and Fos protein in PrRP neurons after food intake as a marker of neuronal activation. Refeeding following a 24-hour fast increased the percentage of $\mathrm{p}$-CREB-positive PrRP neurons in the NTS (Figure 5A). The number of Fos-positive PrRP neurons in the NTS also significantly increased after refeeding (Figure 5B). By contrast, there were no significant increases in the percentages of $\mathrm{P}$-CREB-positive PrRP neurons either in the ventrolateral medulla oblongata $(89.6 \% \pm 3.6 \%$ [control] and $90.1 \% \pm 2.1 \%$ [refeeding]) or in the dorsomedial hypothalamus following refeeding $(3.0 \% \pm 1.5 \%$ [control] and $2.4 \% \pm 1.1 \%$ [refeeding]). The number of Fos-positive PrRP neurons was increased slightly in the ventrolateral medulla oblongata $(0 \pm 0$ cells/rat [control] and $2.8 \pm 1.2$ cells $/$ rat [refeeding]; $P<0.05)$ but not in the dorsomedial hypothalamus following refeeding $(1.0 \pm 1.0$ cells/rat [control] and $5.0 \pm 2.0$ cells/rat [refeeding]).

Food intake after impairment of PrRP signaling. Up to the age of 14 weeks, the daily food intake of PrRP-deficient mice was not sig-
Table 1

$\mathrm{VO}_{2}$ and respiratory exchange ratios in pair-fed PrRP-deficient and WT mice

\begin{tabular}{lcccc} 
& \multicolumn{2}{c}{$\mathbf{V O}_{\mathbf{2}}\left(\mathbf{m l} / \mathbf{k g}^{0.75}\right.$ per hour } & \multicolumn{2}{c}{ Respiratory exchange ratio } \\
& WT & PrRP-deficient & WT & PrRP-deficient \\
Standard chow $(n=6$ or 7$)$ & $1,466 \pm 73$ & $1,331 \pm 82$ & $0.86 \pm 0.02$ & $0.83 \pm 0.01$ \\
High-fat diet $(n=4)$ & $1,485 \pm 118$ & $1,535 \pm 58$ & $0.80 \pm 0.01$ & $0.78 \pm 0.01$ \\
\hline
\end{tabular}

Data are expressed as mean \pm SEM. 

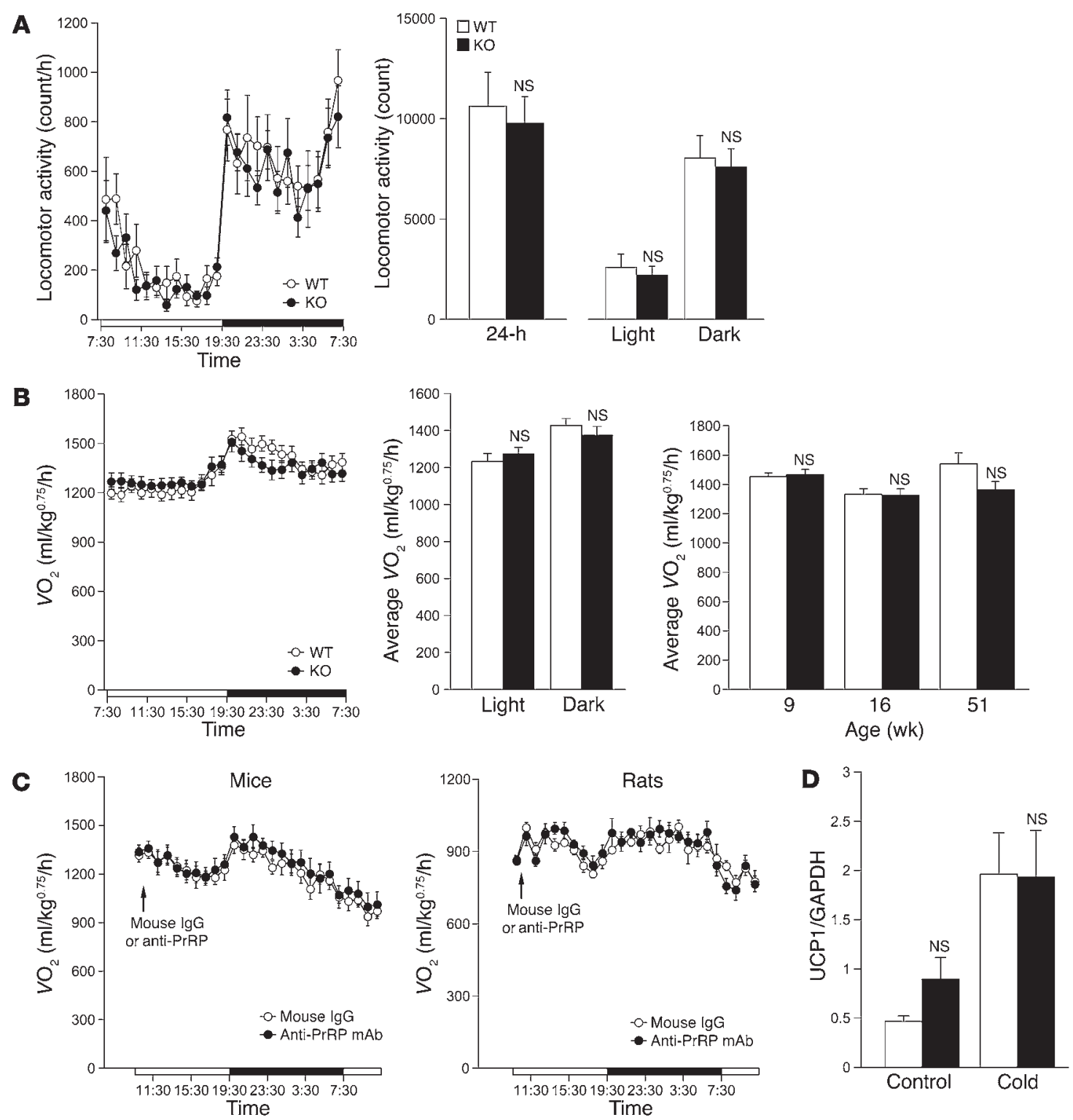

\section{Figure 4}

Energy consumption of PrRP-deficient mice. (A) At the age of 16 weeks, locomotor activity was not significantly different in WT and PrRPdeficient mice $(n=7)$. (B) $V O_{2}$ was not significantly different in WT and PrRP-deficient mice at the age of 9 ( $n=9$ or 11 ; right), 16 ( $n=9$ or 11 ; left, middle, and right), and 51 weeks ( $n=5$ or 6 ; right). (C) $V_{2}$ was not significantly different in 10- to 11-week-old mice (left) and 12-week-old rats (right) that received an i.c.v. injection of anti-PrRP mAb (mice, $n=8$; rats, $n=4$ ). (D) Exposure to a cold environment increased UCP1 mRNA expression in the BAT similarly in WT and PrRP-deficient mice at the age of 24 weeks $(n=4)$. Error bars indicate SEM. NS, $P>0.05$ versus WT mice.

nificantly different from that of WT mice. However, even at this young age when no obesity was evident, PrRP-deficient mice ate significantly more after a 24-hour fast than WT mice (Figure 5C), suggesting that PrRP is involved in food intake when food intake is facilitated by fasting. At the age of 24 weeks, PrRP-deficient mice ate more food than WT mice (Figure 5D).

We then examined food intake in rats whose endogenous PrRP functions were acutely blocked by neutralizing PrRP mAb. Rats pretreated with anti-PrRP $\mathrm{mAb}$ ate more during the dark period than control rats, whether anti-PrRP $\mathrm{mAb}$ was injected immediately before the dark period or during the light period (Figure 5,
$\mathrm{E}$ and F). Rats injected intracerebroventricularly (i.c.v.) with antiPrRP $\mathrm{mAb}$ ate more after a 24-hour fast as measured either during the dark or the light period (Figure 5, G and H). Thus, immunoneutralization of central PrRP facilitates food intake whether meal initiation is triggered by the onset of the dark period or by fasting. Total daily food intake can be considered as the product of meal size and meal frequency. We investigated meal pattern in PrRP-deficient mice (Figure 5I) and in rats injected with anti-PrRP $\mathrm{mAb}$ (Figure 5J). The meal size, but not the meal frequency, was higher in PrRP-deficient mice than in WT mice and in rats was increased after i.c.v. injection of anti-PrRP $\mathrm{mAb}$. 

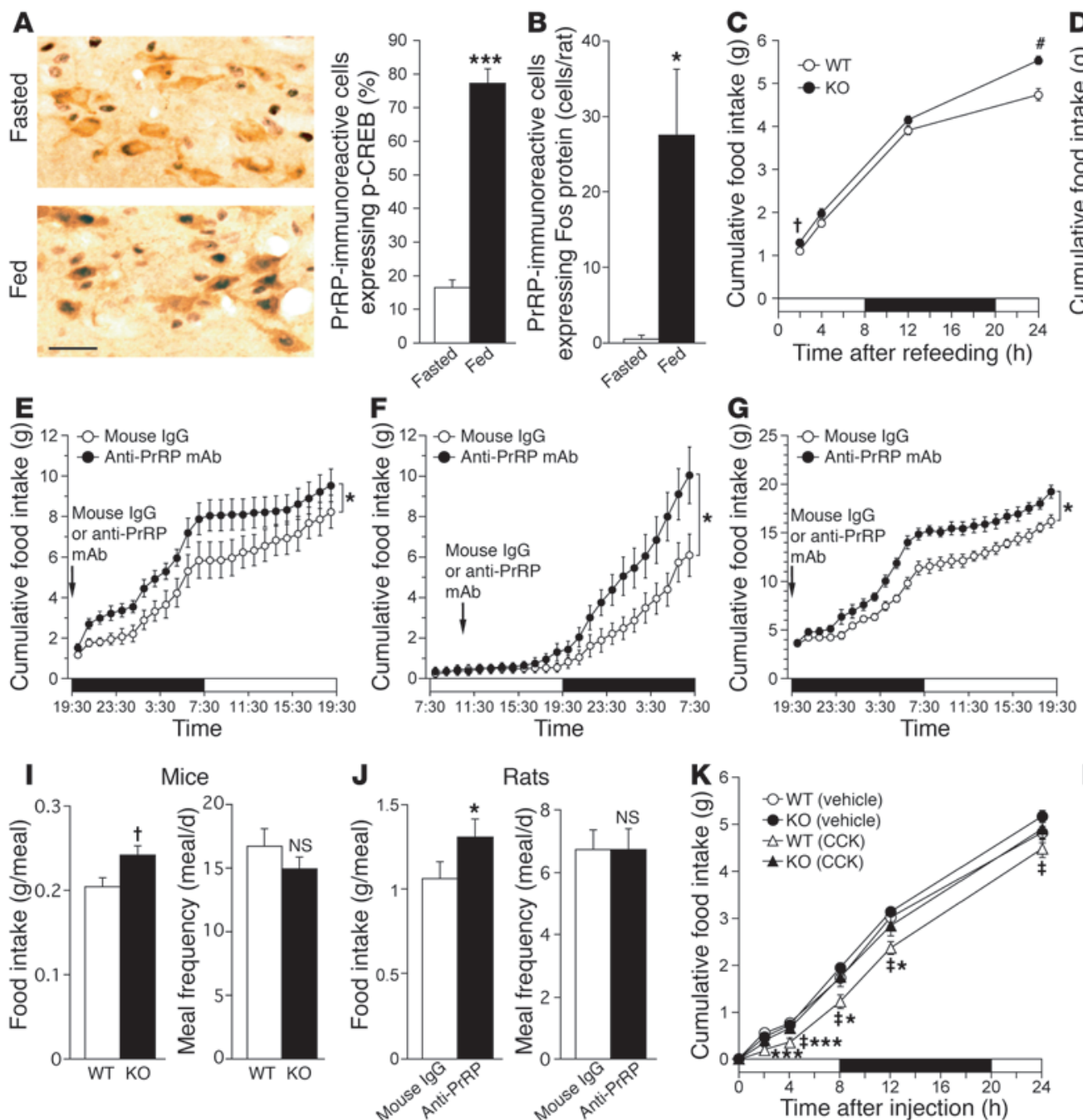

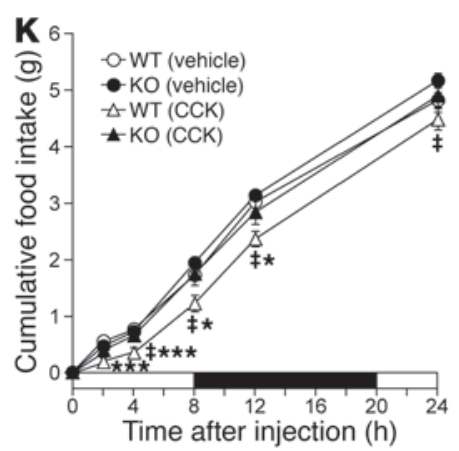

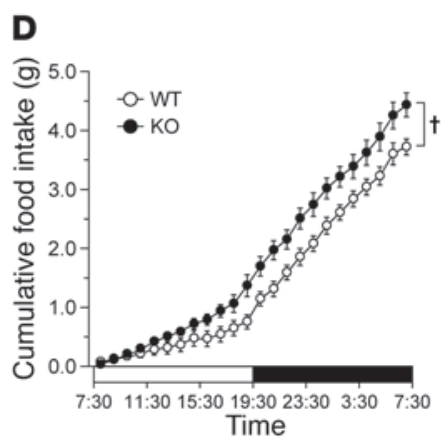

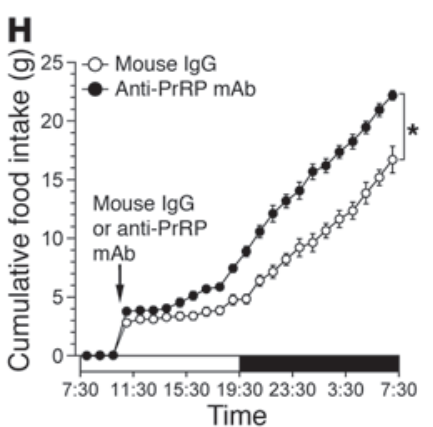

$\mathbf{L}$

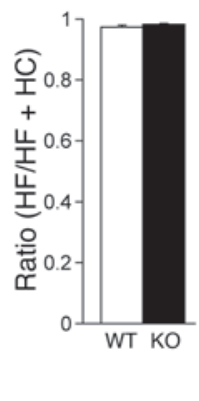

Figure 5

Role of endogenous PrRP in food intake. (A and B) Food intake increased the percentage of PrRP neurons expressing $p$-CREB (A; $n=7$ or 9 ) and the number of Fos-positive PrRP neurons (B; $n=7$ or 8 ) in the rat NTS. Photographs show PrRP neurons (brown cytoplasmic reactions) in the NTS. A dark nuclear reaction indicates p-CREB immunoreactivity. Scale bar: $30 \mu \mathrm{m}$. (C) Food intake after a 24-hour fast in WT and PrRPdeficient mice at the age of 14 weeks. Food intake was greater in PrRP-deficient mice $(n=9$ or 10). (D) Cumulative food intake of WT and PrRP-deficient mice at the age of 24 weeks. PrRP-deficient mice ate more food $(n=8)$. $(\mathbf{E}-\mathbf{H})$ Cumulative food intake of rats injected i.c.v. with anti-PrRP mAb or mouse IgG at the beginning of the dark period ( $\mathbf{E}$ and $\mathbf{G})$ or 3 hours after the beginning of the light period $(\mathbf{F}$ and $\mathbf{H})$. Rats in $\mathbf{G}$ and $\mathbf{H}$ were fasted before the i.c.v. injection $(n=8$ or 9$)$. (I and $\mathbf{J})$ Meal size but not meal frequency was greater in PrRP-deficient mice (14 weeks old; $n=6$ or 10 ) or rats injected i.c.v. with anti-PrRP mAb (10 weeks old; $n=8$ ) than in control WT mice or control rats. (K) Cumulative food intake of WT mice or PrRP-deficient mice injected i.p. with CCK at the age of 19-21 weeks. Suppression of food intake by CCK was blocked in PrRP-deficient mice ( $n=6$ or 7 ). The intake ratio of high-fat diet (L) or tallow (M) was not significantly different in WT and PrRP-deficient mice at the age of 34-37 weeks $(n=4)$. Error bars indicate SEM. ${ }^{\dagger} P<0.05,{ }^{\ddagger} P<0.01,{ }^{\#} P<0.001$ versus WT mice; ${ }^{\star} P<0.05,{ }^{* * *} P<0.001$ versus fasted rats, mouse IgG-injected rats, or vehicle-injected mice. HC, high-carbohydrate diet.

PrRP neurons are activated after systemic injections of the peripheral satiety signal CCK (11). We therefore measured the effects of systemic administration of CCK on food intake in mice that had been fasted for 24 hours. CCK had less effect on food intake in PrRP-deficient mice than in WT mice (Figure 5K), suggesting that PrRP mediates a satiety signaling of CCK.

To investigate whether PrRP-deficient mice have enhanced fat preference, mice were tested on 2-choice macronutrient diet; they were given free access to both high-fat and high-carbohydrate diets or to both tallow and standard diet. There was no significant dif- ference between WT and PrRP-deficient mice in the intake ratio of high-fat food (Figure 5L) or tallow (Figure 5M), suggesting that PrRP-deficient mice had no enhanced preference for fat meals.

Food intake-related peptides in the bypothalamus. We examined the expression of appetite-regulating peptides in the hypothalamus using in situ hybridization histochemistry. In obese PrRP-deficient mice fed a high-fat diet, the expression of mRNA for the anorexigenic peptide corticotrophin-releasing hormone (CRH) in the hypothalamic paraventricular nucleus was not different as compared with that in WT mice (Table 2). In nonobese PrRP-defi- 
Table 2

Expression of appetite-related peptides in the hypothalamus

$\begin{array}{cccrcrr} & \text { AgRP } & \text { NPY } & \text { Orexin } & \text { CART } & \text { CRH } & \text { POMC } \\ \text { STD } & & & & & & \\ \text { WT } & 100 \pm 14 & 100 \pm 16 & 100 \pm 2 & 100 \pm 12 & 100 \pm 8 & 100 \pm 7 \\ \text { KO } & 79 \pm 4 & 96 \pm 211 & 3 \pm 2 & 126 \pm 8 & 70 \pm 2 & 95 \pm 5 \\ \text { HF } & & & & & & \\ \text { WT } & 98 \pm 9 & 89 \pm 9 & 109 \pm 9 & 108 \pm 11 & 87 \pm 9 & 78 \pm 7 \\ \text { KO } & 93 \pm 29 & 8 \pm 11 & 105 \pm 7 & 136 \pm 14 & 82 \pm 5 & 94 \pm 5\end{array}$

Values are expressed as the mean percentage of probe binding as compared with that in WT mice fed standard chow. Mean levels of mRNAs $( \pm$ SEM) for AgRP, NPY, CART, and POMC in the arcuate; orexin in the lateral hypothalamus; and $\mathrm{CRH}$ in the paraventricular nucleus in mice at the age of 16 weeks given free access to standard chow or high-fat diet for 4 weeks. There were no significant differences between WT mice and PrRP-deficient (KO) mice $(n=4)$. STD, standard chow; HF, high-fat diet.

cient mice fed standard laboratory chow at the age of 16 weeks, the CRH mRNA expression level was slightly decreased (Table 2), but the difference was not statistically significant $(P=0.055)$. We also measured the mRNA expression levels of 2 anorexigenic peptides, proopiomelanocortin (POMC) and cocaine- and amphetamine-regulated transcript (CART) and 2 orexigenic peptides, agouti-related protein (AgRP) and neuropeptide Y (NPY) in the arcuate nucleus and measured orexin mRNA expression in the lateral hypothalamus; there were no significant differences in any of these expression levels between PrRP-deficient mice and WT mice fed on either standard chow or high-fat diet (Table 2).

Leptin effects on $B W$ and food intake in PrRP-deficient mice. An abnormality in satiety signaling alone does not necessarily cause obesity (23), unless it affects fundamental homeostatic mechanisms. As leptin is particularly important for long-term metabolic homeostasis, we examined whether leptin administration activates PrRP neurons. Leptin induced expression of p-STAT3 in PrRP-expressing neurons of the NTS and dorsomedial hypothalamus (Figure 6A). We then examined effects of leptin administration in PrRP-deficient mice. Peripheral or central administration of leptin reduced food intake and BW in WT mice. These effects were much impaired in PrRP-deficient mice (Figure 6, B-E), suggesting that PrRP is important for relaying leptin signaling to reduce food intake and BW.

\section{Discussion}

PrRP is expressed in subpopulations of neurons in the NTS, the ventrolateral medulla, and the dorsomedial hypothalamus and has been implicated in several physiological processes $(24,25)$, including satiety signaling $(10-13,22)$, stress-induced release of ACTH and oxytocin $(16,19,26,27)$, and nociception (20). In the present study, most of the PrRP neurons in the NTS were activated after initiation of food intake, with no significant activation of PrRP neurons in the hypothalamus. Perturbation of PrRP signaling either by gene KO or by administration of neutralizing PrRP $m A b$ increased amounts of food intake per meal but not meal frequencies. These data suggest that PrRP release from NTS neurons is a central satiety signal.

PrRP-deficient mice showed adult-onset hyperphagia and obesity and exhibited an accompanying impaired glucose tolerance and insulin resistance. These data are consistent with reports that mice deficient in GPR10, the PrRP receptor, become obese in adulthood $(15,21)$. Although PrRP administration has been reported previously to increase energy consumption (13), $\mathrm{VO}_{2}$ was not significantly changed in PrRP-deficient mice in the present study. Neither body temperature changes during exposure to a cold environment nor cold exposure-induced increase in UCP1 mRNA were different in WT and PrRPdeficient mice. Locomotor activity was also unchanged in PrRP-deficient mice. Furthermore, pair feeding abolished the induction of obesity in PrRP-deficient mice. These data suggest that PrRP-deficient mice gain more weight than WT mice as a result of the increased food intake rather than reduced energy expenditure.

In the present study, blocking PrRP signaling in rats by administration of anti-PrRP mAb facilitated food intake only when food intake was initiated by the onset of the dark period or by fasting, suggesting that blocking PrRP actions does not itself initiate feeding but instead that feeding continues for longer once initiated. This suggests that PrRP might be involved in satiety signaling - a conclusion supported by the observation that CCK-induced reduction in food intake was impaired in PrRP-deficient mice. These findings are consistent with reports that GPR10-deficient mice have impaired responses to CCK (22). As peripheral administration of CCK activates most of the PrRP neurons in the medulla oblongata (11), these data suggest that PrRP/GPR10 systems mediate the satiety-inducing effects of peripheral CCK. We also found that PrRP-deficient mice showed an increase in meal size rather than meal frequency, similar to observations in $\mathrm{CCK}_{\mathrm{A}}$ receptor-deficient mice (23), indicating that CCK/PrRP signaling is important for determining meal size.

PrRP is localized in the A2 noradrenergic neurons of the NTS, in the A1 noradrenergic neurons of the ventrolateral medulla, and in neurons in the dorsomedial hypothalamus $(6,8,9)$. Meal consumption activates neurons in the NTS $(28,29)$, including in particular noradrenergic neurons (30). In part, this reflects activation of satiety pathways arising from the gastric vagus, which are responsive to CCK. Thus, peripheral administration of CCK activates noradrenergic neurons in the NTS (5), and these neurons are critical for CCK signaling $(31,32)$. Here we show that food intake rapidly activates PrRP neurons in the NTS. The data suggest that PrRP neurons in the NTS mediate satiety signaling and support the view that satiety circuits are activated coincidentally with food intake (30). At present, the precise mechanisms by which PrRP reduces food intake remain to be clarified. PrRP may convey satiety signals to the hypothalamus (22), but microinjection of PrRP into the dorsal motor nucleus of the vagus also modulates gastric motor function (33). It is thus also possible that PrRP may inhibit food intake via an action on gastric emptying.

Mice deficient in $\mathrm{CCK}_{\mathrm{A}}$ receptors do not show obesity (23), so the defects in $\mathrm{CCK}_{\mathrm{A}}$ receptor signaling in PrRP-deficient or GPR10-deficient mice might not fully explain the obesity observed in PrRP-deficient mice. Leptin administration induces nuclear translocation of STAT3 in the dorsomedial hypothalamus (34) and p-STAT3 expression in the NTS (35), where PrRP neurons are localized. PrRP neurons express leptin receptors (25), and leptin administration increases PrRP mRNA (36), suggesting that the activity of PrRP neurons is under the control of leptin. Here we showed that leptin induces p-STAT3 expression in PrRP neurons, especially in the dorsomedial hypothalamus, and that the leptininduced reduction in food intake and BW is impaired in PrRP-deficient mice. These data suggest that PrRP neurons, especially those in the dorsomedial hypothalamus, might be an important target 
A

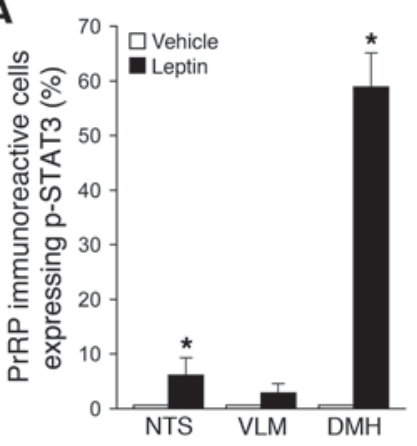

B

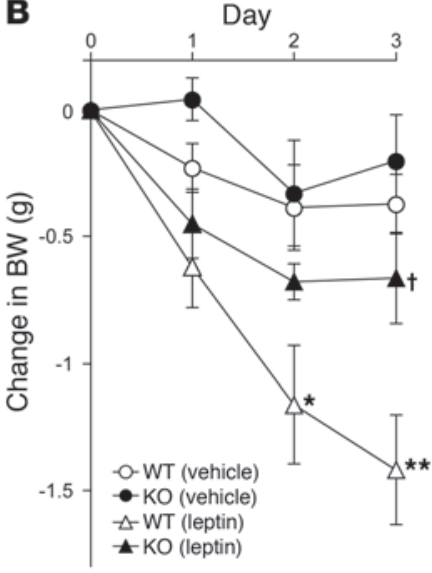

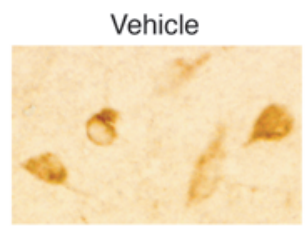

Leptin

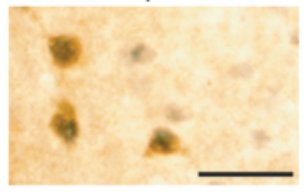

C

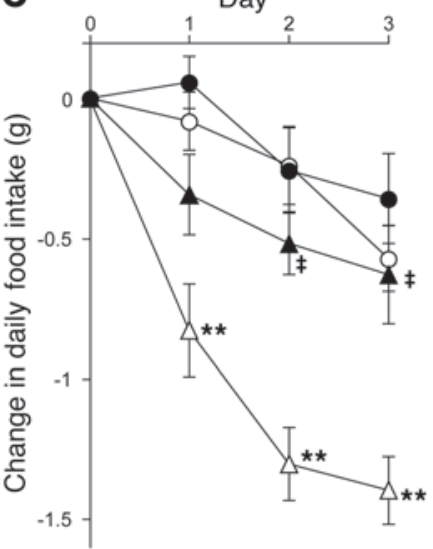

D

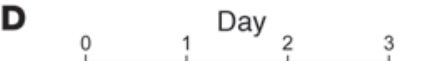

E

E $\quad 0_{1}$ Day $_{2} \quad 3$

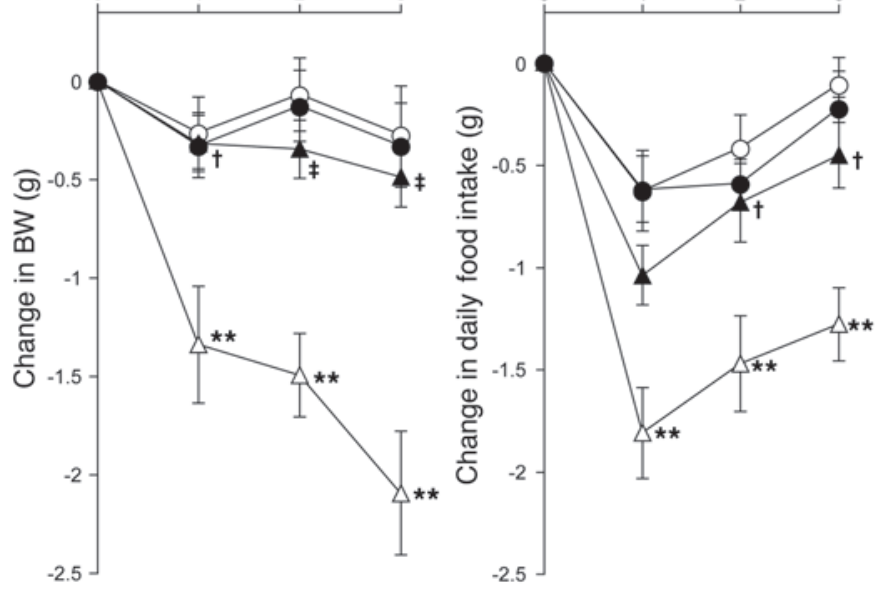

of leptin's actions to restrain food intake or that leptin modulates the effects of PrRP by its actions on the neuronal targets of PrRP.

GPR10-deficient mice show reduced energy expenditure (15), and as acute administration of PrRP increases $V \mathrm{O}_{2}(13)$, these data suggest that PrRP plays a role in energy expenditure. However, in the present study, $V \mathrm{O}_{2}$ was not different in WT and PrRP-deficient mice, and acute blockade of PrRP signaling by anti-PrRP $\mathrm{mAb}$ did not increase $\mathrm{VO}_{2}$. Furthermore, the obesity observed in PrRPdeficient mice could be fully reversed by pair feeding. These data suggest that endogenous PrRP does not play an important role in energy expenditure in basal conditions. The apparent discrepancies concerning energy expenditure between GPR10-deficient and PrRP-deficient mice remain to be clarified.

\section{Figure 6}

Changes in BW and food intake after leptin administration. (A) Expression of p-STAT3 in PrRP neurons following i.c.v. injection of leptin in C57BL/6N mice (11 weeks old). Leptin increased the percentage of PrRP neurons expressing p-STAT3 in the NTS and dorsomedial hypothalamus (DMH) but not in the ventrolateral medulla oblongata (VLM) $(n=4)$. Photographs show PrRP neurons (brown cytoplasmic reactions) in the $\mathrm{DMH}$. A dark nuclear reaction indicates p-STAT3 immunoreactivity. Scale bar: $30 \mu \mathrm{m}$. BW (B) and food intake (C) of WT or PrRP-deficient mice injected i.p. with leptin at the age of 16 weeks. The effects of leptin on BW and food intake were attenuated in PrRP-deficient mice $(n=7)$. BW (D) and food intake (E) of WT or PrRP-deficient mice injected i.c.v. with leptin at the age of $18-19$ weeks. The effects of i.c.v. leptin on BW and food intake were attenuated in PrRP-deficient mice $(n=9-20)$. Error bars indicate SEM. ${ }^{\dagger} P<0.05,{ }^{\ddagger} P<0.01$ versus WT mice; ${ }^{\star} P<0.05$, ${ }^{* *} P<0.01$ versus vehicle-injected mice.

Energy homeostasis is regulated by various orexigenic and anorexigenic peptides in the hypothalamus. Administration of PrRP activates CRH neurons in the hypothalamus (37), and PrRP-induced anorexia is attenuated by a CRH receptor antagonist (13). However, in the present study, there was no significant decrease in CRH mRNA expression in the paraventricular nucleus, suggesting that changes in $\mathrm{CRH}$ neuronal activity may not be the main cause of obesity in PrRP-deficient mice. We also found that the expression levels of mRNAs encoding appetite-regulating peptides, AgRP, NPY, orexin, CART, and POMC, were normal in PrRP-deficient mice, indicating that the hyperphagia observed in PrRP-deficient mice is unlikely to be the result of a grossly perturbed functioning of these hypothalamic neuronal populations.

Both PrRP-deficient mice and GPR10-deficient mice show adult-onset obesity $(15,21)$, but there are several differences. Hyperphagia is not obvious in GPR10-deficient mice (22) but is clear in PrRP-deficient mice, and a high-fat diet can induce obesity in PrRP-deficient but not in GPR10-deficient mice (21). It is possible that PrRP acts on not only GPR10 but also other receptors, including neuropeptide FF receptor 2 (38). Administration of PrRP reduces food intake in rats with a naturally occurring polymorphism of the Prlbr gene that abolishes its ability to bind PrRP (39), suggesting that receptors other than GPR10 also play a role in the action of PrRP on feeding behavior. It is also possible that ligands other than PrRP might exist for GPR10. In conclusion, this study indicates that PrRP is a potent satiety peptide in the rodent CNS that contributes to the determination of meal size and that perturbation of PrRP signaling can predispose to obesity, mainly due to hyperphagia.

\section{Methods}

Generation of PrRP-deficient mice. To construct the targeting vector, a Prlh genomic clone was isolated from a 129/Svj-derived RW-4 ES cell genomic library. The Prlh gene targeting vector was designed to replace a $2.0-\mathrm{kb}$ BamHI-HpaI fragment including exons 1 and 2 constituting the entire coding region, with a neomycin phosphotransferase resistance cassette (neo). A 2.1-kb VspI-BamHI fragment was used as the $5^{\prime}$ homology region and a 5.0-kb HpaI-EcoRI fragment was used as the $3^{\prime}$ homology region. We linearized the targeting vector and electroporated it into RW-4 ES cells (Genome Systems Inc.). We selected G418-resistant clones and screened them by Southern blot analysis. Heterozygous ES cell clones were injected into blastocysts of C57BL/6N mice (Charles River Laboratories) and trans- 
ferred into uteri of pseudopregnant females. Chimeric males were mated to $\mathrm{C} 57 \mathrm{BL} / 6 \mathrm{~N}$ females, and the resulting heterozygous mice were intercrossed. Their offspring were screened by Southern blot analysis. PrRP-deficient mice backcrossed into C57BL/6N background for 8 generations were used in this study. Permission of Takeda Chemical Industries Ltd. is necessary for the distribution of PrRP-deficient mice.

Animals. Animals were housed in a temperature- $\left(22 \pm 2^{\circ} \mathrm{C}\right)$ and humidity-controlled (40\%-70\%) room with a 12 -hour light/12-hour dark cycle (light on 7:30-19:30). Food and water were available ad libitum. All animal procedures were approved by the Judging Committee of Experimental Animal Ethics of Jichi Medical University and were in accordance with Japanese legislation concerning animal experiments.

Intraperitoneal glucose tolerance test and insulin tolerance test. For the glucose tolerance test, male WT and PrRP-deficient mice (39-40 weeks old) were fasted for 14 hours (23:00-13:00) and injected i.p. with glucose $(2 \mathrm{~g} / \mathrm{kg}$ $\mathrm{BW})$. For the insulin tolerance test, male mice (40-41 weeks old) were fasted for 4 hours (9:00-13:00) and then injected i.p. with insulin $(1 \mathrm{U} / \mathrm{kg}$ BW; Novolin; Novo Nordisk). For both tests, blood samples were taken from the tail vein at $0,15,30,60$, and 120 minutes after loading. Blood glucose concentrations were determined by an enzymatic method using a GLUCOCARD DIA meter (ARKRAY).

High-fat diet. Male WT mice or PrRP-deficient mice were given either standard laboratory chow (CE-2; CLEA Japan) or a high-fat diet (Quick Fat; CLEA Japan) from the age of 5 weeks or for 4 weeks from the age of 12 weeks. The standard laboratory chow contains $12 \%$ fat, $29 \%$ protein, and $59 \%$ carbohydrates, with a caloric density of $3.45 \mathrm{kcal} / \mathrm{g}$. The highfat diet has $31 \%$ fat, $24 \%$ protein, and $45 \%$ carbohydrates, with a caloric density of $4.11 \mathrm{kcal} / \mathrm{g}$.

Pair feeding. Male WT and PrRP-deficient mice were housed individually from 6 weeks of age, provided with food ad libitum, and weighed weekly. Pair feeding of standard laboratory chow or high-fat diet was started at the age of 12 weeks.

Surgery and i.c.v. injection of an anti-PrRP $m A b$. Male animals were anesthetized with Avertin ( $200 \mathrm{mg} / \mathrm{kg} \mathrm{BW}$, i.p.; tribromoethanol; Sigma-Aldrich) and placed in a stereotaxic frame. Stainless steel guide cannulae (25-gauge [mice] or 23-gauge [rats]) were inserted into the right lateral cerebral ventricle (mice: $0.4 \mathrm{~mm}$ caudal to bregma, $1.0 \mathrm{~mm}$ lateral to the midline, and $2.0 \mathrm{~mm}$ below the skull; rats: $0.6 \mathrm{~mm}$ caudal to bregma, $1.6 \mathrm{~mm}$ lateral to the midline, and $4.5 \mathrm{~mm}$ below the skull) and secured to the skull with screws and dental cement. The position of the tip was verified with methylene blue injected through the cannulae after experiments. Animals were allowed to recover for 1 week. Animals were injected i.c.v. with anti-PrRP $\mathrm{mAb}(2 \mu \mathrm{l}$ [mice] or $8 \mu \mathrm{l}$ [rats]; $4.9 \mathrm{mg} / \mathrm{ml}$ P2L-1C; Takeda Pharmaceutical Co.) $(8,19,26,37)$ or control IgG $(4.9 \mathrm{mg} / \mathrm{ml}$ mouse IgG; Sigma-Aldrich) via inner cannulae (32-gauge [mice] or 30-gauge [rats]). Permission of Takeda Chemical Industries Ltd. is necessary for the distribution of antiPrRP mAb (P2L-1C).

Locomotor activity and $\mathrm{VO}_{2}$. Spontaneous motor activity was recorded in the home cage by the activity sensor unit (O'hara and Co.) (40). $\mathrm{VO}_{2}$ and carbon dioxide production $\left(V \mathrm{CO}_{2}\right)$ were measured simultaneously for 4 animals using an indirect calorimeter (Oxymax Equal Flow System; Columbus Instruments) with an airflow of $0.8 \mathrm{l} / \mathrm{min}$ (mice) or $2 \mathrm{l} / \mathrm{min}$ (rats). Animals were placed in individual calorimeter chambers. After a 2-hour acclimation period, $V \mathrm{O}_{2}\left(\mathrm{ml} / \mathrm{kg} \mathrm{BW}^{0.75}\right.$ per hour) was measured every 5 minutes for 24 hours. In the experiments with WT and PrRP-deficient mice, the measurements were conducted in male mice with free access to food $(9,16$, and 51 weeks old) or under pair-fed conditions (52-54 weeks old). In the experiments with an i.c.v. injection, anti-PrRP $\mathrm{mAb}$ or mouse IgG was injected i.c.v. into male mice (10-11 weeks old; C57BL/6N; Charles River Laboratories) or male rats (12 weeks old, std:Wistar; SLC Japan) after a 1-hour baseline measurement of $\mathrm{VO}_{2}$, and the measurements were conducted in animals with no access to food. The $\mathrm{VO}_{2}$ values from 12 consecutive readings, encompassing a 1-hour period, were averaged for analysis. The respiratory exchange ratio was calculated as $\mathrm{VCO}_{2} / \mathrm{VO}_{2}$.

Exposure to a cold environment. Male WT or PrRP-deficient mice (24 weeks old) were placed in an incubator at $2^{\circ} \mathrm{C}$ for 6 hours. Body temperature was measured with a rectal temperature probe (model BDT-100; BRC). For measurements of Ucp1 mRNA, mice were deeply anesthetized i.p. with pentobarbital $(50 \mathrm{mg} / \mathrm{kg}$ BW; Nembutal; Dainippon Pharmaceutical) 24 hours after the cold exposure, and the BAT was obtained. The total RNA of the BAT was isolated using TRIzoL (Invitrogen) and treated with RQ1-DNase (Promega) to remove residual contamination with DNA. First-strand cDNA synthesis was completed using ReverTra Ace (Toyobo). Primers for quantitative RT-PCR were first examined by HotStarTaq DNA polymerase $\left(94^{\circ} \mathrm{C}\right.$ for 15 seconds, $60^{\circ} \mathrm{C}$ for 20 seconds, and $72^{\circ} \mathrm{C}$ for 20 seconds $\times 30$ cycles; QIAGEN) and agarose gel electrophoresis for correct product size and absence of primer-dimer formation. Using a QuantiTect SYBR Green PCR kit (QIAGEN), quantitative RT-PCRs $\left(95^{\circ} \mathrm{C}\right.$ for 15 seconds, $60^{\circ} \mathrm{C}$ for 20 seconds, and $72^{\circ} \mathrm{C}$ for 20 seconds $\times 40$ cycles) were performed in an ABI-Prism 7700 sequence detector (Applied Biosystems). Product accumulation was measured in real time, and the mean Ct was determined for replicate samples on the same plate. Different cDNA samples were normalized using primer sets to Gapdh. Primers for Gapd $b$ were $5^{\prime}$-GGCACAGTCAAGGCTGAGAATG-3' and $5^{\prime}$-ATGGTGGTGAAGACGCCAGTA-3'; those for Ucp1 were $5^{\prime}$-CGACAACTTCCGAAGTGCAAC- $3^{\prime}$ and $5^{\prime}$-TGGATCTGAAGGCGGACTTT-3'

Detection of activated PrRP neurons after food intake. To detect $\mathrm{p}$-CREB in PrRP neurons, male rats (9 weeks old, std:Wistar; SLC Japan) were anesthetized with Avertin, and polyethylene catheters (PE50; BD) were inserted into the right jugular vein. Seven days later, the rats were fasted for 24 hours (19:30-19:30). One group of rats was refed for 30 minutes after the fast, anesthetized with pentobarbital (60 mg/kg BW, i.v.), and perfused transcardially with heparinized saline $(20 \mathrm{U} / \mathrm{ml})$, followed by $3.75 \%$ acrolein and $2 \%$ PFA in $0.1 \mathrm{M}$ phosphate buffer ( $\mathrm{pH} 7.4$ ). The brains were removed, postfixed in $3.75 \%$ acrolein and $2 \%$ PFA overnight, and transferred to $30 \%$ sucrose solution in $0.1 \mathrm{M}$ phosphate buffer until tissue sank. The brains were frozen on dry ice and stored at $-80^{\circ} \mathrm{C}$. Coronal sections were cut at $30 \mu \mathrm{m}$ with a freezing sledge microtome. Every fourth section of the hypothalamus and the medulla oblongata was collected and processed for immunohistochemistry. Sections were pretreated with $0.5 \%$ sodium metaperiodate for 20 minutes and with $1 \%$ sodium borohydride for 20 minutes. The sections were incubated for 15 minutes with $1.5 \% \mathrm{H}_{2} \mathrm{O}_{2}$ solution to block endogenous peroxidase, with $10 \%$ normal goat serum for 1 hour, and then with a rabbit polyclonal $\mathrm{Ab}$ against p-CREB (diluted 1:200; Ser133; Cell Signaling Technology) for 48 hours at $4{ }^{\circ} \mathrm{C}$, followed by incubation with biotinylated goat anti-rabbit IgG $(2 \mu \mathrm{g} / \mathrm{ml}$ BA-1000; Vector Laboratories) for 2 hours and then with avidinbiotinylated horseradish peroxidase complex (VECTASTAIN Elite ABC Kit; Vector Laboratories) for 30 minutes at room temperature. p-CREB immunoreactivity was visualized as a black nuclear precipitate using a glucose oxidase-based, nickel-intensified, $3,3^{\prime}$-diaminobenzidine procedure. p-CREB immunolabeled sections were treated with $1.5 \% \mathrm{H}_{2} \mathrm{O}_{2}$ and $10 \%$ normal horse serum and then incubated with a mouse antiPrRP mAb $(5 \mu \mathrm{g} / \mathrm{ml}$ P2L-1T; Takeda Pharmaceutical Co.) for 48 hours at $4^{\circ} \mathrm{C}(6)$, followed by incubation with biotinylated horse anti-mouse IgG $(1 \mu \mathrm{g} / \mathrm{ml} \mathrm{BA}-2001$; Vector Laboratories) and then with avidin-biotinylated horseradish peroxidase complex for 30 minutes at room temperature. PrRP immunoreactivity was visualized as a brown cytoplasmic precipitate using a 3,3'-diaminobenzidine procedure. For detection of Fos protein in PrRP neurons, male rats ( 9 weeks old, std:Wistar; SLC Japan) were fasted 
for 24 hours (10:00-10:00). One group of rats was refed for 2 hours after the fast, anesthetized i.p. with pentobarbital, and perfused with acrolein and PFA. Coronal brain sections were cut at $30 \mu \mathrm{m}$ with a freezing sledge microtome. Every fourth section of the hypothalamus and the medulla oblongata was collected and processed for immunohistochemistry. Following treatments with sodium metaperiodate, sodium borohydride, and $\mathrm{H}_{2} \mathrm{O}_{2}$, the sections were incubated with $10 \%$ normal goat serum and incubated with a rabbit polyclonal $\mathrm{Ab}$ against Fos protein (diluted 1:10,000; Oncogene) for 48 hours at $4{ }^{\circ} \mathrm{C}$. The sections were incubated overnight with peroxidase-labeled goat anti-rabbit IgG $(1 \mu \mathrm{g} / \mathrm{ml}$ PI-1000; Vector Laboratories) at $4{ }^{\circ} \mathrm{C}$. Fos immunoreactivity was visualized as a black nuclear precipitate using a glucose oxidase-based, nickel-intensified, 3,3'-diaminobenzidine procedure. Fos-immunolabeled sections were treated for detection of PrRP immunoreactivity, as described above. The number of PrRP-positive cells that were positive or negative for $\mathrm{p}$-CREB or Fos protein was determined, and the percentage of PrRP-positive cells expressing p-CREB was calculated for each rat. Fourteen sections of the caudal brainstem (between $-1,560 \mu \mathrm{m}$ and $0 \mu \mathrm{m}$ relative to the obex) were examined in each rat. For the dorsomedial hypothalamus, cells were counted in 3 sections per rat at a $120-\mu \mathrm{m}$ interval to give a mean value for each rat; these values were averaged to determine a group mean. Permission of Takeda Chemical Industries, Ltd. is necessary for the distribution of anti-PrRP mAb (P2L-1T).

Measurements of food intake after i.c.v. injection of an anti-PrRP $m A b$. Seven days after cannula implantation, male rats (10 weeks old, std:Wistar; SLC Japan) were injected i.c.v. with anti-PrRP $\mathrm{mAb}$ or control IgG, and cumulative food intake was measured by an automatic food counter (O'hara and Co.). An i.c.v. injection was performed at the beginning of the dark period or 3 hours after the onset of the light period. Half of the rats were fasted for 24 hours until the i.c.v. administration.

Measurements of meal size and meal frequency. Food intake was recorded every minutes by an automatic food counter (O'hara and Co.). For male WT and PrRP-deficient mice (14 weeks old), meal initiation was defined as more than $50 \mathrm{mg}$ pellets within 10 minutes. Once a meal was initiated, meal termination was defined as the onset of a 10-minute interval with no intake. For male rats (10 weeks old, std:Wistar; SLC Japan), meal initiation was defined as a minimum of $100 \mathrm{mg}$ pellets within 10 minutes.

Administration of CCK. Male WT and PrRP-deficient mice (19-21 weeks old) were individually housed, deprived of food for 24 hours, and injected i.p. at 11:00 with saline or CCK-octapeptide $26-33$ (sulfated form) $(20 \mu \mathrm{g} /$ $\mathrm{kg}$ BW; Peptide Institute). Cumulative food intake was measured before and after injection.

Two-choice macronutrient diet test. Male WT and PrRP-deficient mice at the age of 34-37 weeks had free access to both high-fat diet (Quick Fat) and high-carbohydrate diet (63.7\% of calories from carbohydrate and $9.6 \%$ of calories from fat, $360.7 \mathrm{kcal} / 100 \mathrm{~g}$; KBT Oriental Co.). Daily food intake was measured for 9 days. Other mice had free access to both standard laboratory chow (CE-2) and tallow. The daily calories from the high-fat diet or tallow were calculated as a ratio of total caloric intake and averaged for the last 2 days.

In situ bybridization. The brains of mice fed either standard laboratory chow or a high-fat diet for 4 weeks from the age of 12 weeks were analyzed for mRNA levels of food intake-related peptides. Semiquantitative in situ hybridization was performed using antisense probes for AgRP, NPY, orexin, CART, CRH, and POMC mRNAs as described in detail previously (41-43). We analyzed the images in an MCID imaging analyzer (Imaging Research Inc.).

Leptin injection and detection of activated PrRP neurons after leptin injection. Murine recombinant leptin (Peprotech) was dissolved in $5 \mathrm{mM}$ sodium citrate buffer $(\mathrm{pH} 4)$ and stored at $-80^{\circ} \mathrm{C}$. Immediately before use, the $\mathrm{pH}$ of the solution was adjusted to 7.0-7.5 by addition of sodium hydroxide. For measurement of BWs and food intake, male WT and PrRP-deficient mice (i.p., 16 weeks old; i.c.v., 18-19 weeks old) were housed individually and injected i.p. at 8:00 and at 18:00 or i.c.v. at 11:00 with vehicle (mixture solution of sodium citrate, $\mathrm{pH} 4$, and $0.01 \mathrm{M}$ sodium hydroxide; final $\mathrm{pH}, 7.2$ ) or leptin (i.p., $2.5 \mathrm{mg} / \mathrm{kg} \mathrm{BW}$ i.c.v., $0.2 \mu \mathrm{g} / 2 \mu \mathrm{l} / \mathrm{mouse}$ ) for 3 days. For detection of PrRP neurons activated after leptin injection, male mice (11 weeks old, C57BL/6N mice (Charles River Laboratories) were injected i.c.v. with leptin $(5 \mu \mathrm{g} / 2 \mu \mathrm{l} /$ mouse $)$ and perfused with acrolein and PFA. Coronal brain sections were cut at $30 \mu \mathrm{m}$ with a freezing sledge microtome. Every second section of the hypothalamus and the medulla oblongata was collected and processed for immunohistochemistry. After treatments with sodium metaperiodate, sodium borohydride, and $\mathrm{H}_{2} \mathrm{O}_{2}$, the sections were blocked in M.O.M Mouse Ig Blocking Reagent (Vector Laboratories), incubated with normal goat serum and then with normal goat serum and P2L-1T for 48 hours at $4^{\circ} \mathrm{C}$, followed by treatment with a peroxidaselabeled polymer conjugated to goat anti-mouse immunoglobulins (EnVision+ system; Dako) for 2 hours at room temperature. PrRP immunoreactivity was visualized as a brown cytoplasmic precipitate using a 3,3'-diaminobenzidine procedure. PrRP-immunolabeled sections were treated with $\mathrm{H}_{2} \mathrm{O}_{2}$ and normal goat serum and then incubated with a rabbit mAb against p-STAT3 (diluted 1:100; Tyr705; Cell Signaling Technology) for 48 hours at $4{ }^{\circ} \mathrm{C}$, followed by treatment with a peroxidase-labeled polymer conjugated to goat anti-rabbit immunoglobulins (EnVision+ system; Dako) for 2 hours at room temperature. p-STAT3 immunoreactivity was visualized as a black nuclear precipitate using a glucose oxidase-based, nickel-intensified, 3,3'-diaminobenzidine procedure. The number of PrRPpositive cells that were positive or negative for P-STAT3 was determined, and the percentage of PrRP-positive cells expressing p-STAT3 was calculated for each mouse. Twenty sections of the caudal brainstem (between $-1,140 \mu \mathrm{m}$ and $0 \mu \mathrm{m}$ relative to the obex) were examined in each mouse. For the dorsomedial hypothalamus, cells were counted in 11 sections per mouse ( $60-\mu \mathrm{m}$ intervals) to give a mean value for each mouse; these values were averaged to determine a group mean.

Statistics. Changes in food intake, BW, blood glucose concentrations, motor activity, and $\mathrm{VO}_{2}$ were analyzed by repeated-measures ANOVA. Other data were analyzed by 1-way ANOVA followed by Scheffé's multiple comparison test or 2-tailed $t$ test. A $P$ value of less than 0.05 was considered statistically significant.

\section{Acknowledgments}

This study was supported in part by a Grant-in-Aid for Scientific Research (C) (18590223, 20590237 to T. Onaka) from the Japan Society for the Promotion of Science; and a Grant-in-Aid for Young Scientists (B) (18790172, 20790194 to Y. Takayanagi) and a Grant-in-Aid for Scientific Research on Priority Areas-System Study on Higher-Order Brain Functions (18020025, 20020023 to T. Onaka) from the Ministry of Education, Culture, Sports, Science and Technology of Japan. We are grateful to Mitsugu Nakata and Takashi Yano (Takeda Pharmaceutical Co. Ltd.) for cooperation in producing the PrRP-deficient mice.

Received for publication December 5, 2007, and accepted in revised form September 17, 2008.

Address correspondence to: Tatsushi Onaka, Division of Brain and Neurophysiology, Department of Physiology, Jichi Medical University, 3311-1 Yakushiji, Shimotsuke, Tochigi 329-0498, Japan. Phone: 81-285-58-7318; Fax: 81-285-44-8147; E-mail: tonaka@jichi.ac.jp. 
1. Murphy, K.G., and Bloom, S.R. 2006. Gut hormones and the regulation of energy homeostasis. Nature. 444:854-859.

2. Schwartz, G.J. 2006. Integrative capacity of the caudal brainstem in the control of food intake. Philos. Trans. R. Soc. Lond. B Biol. Sci. 361:1275-1280.

3. Broberger, C., and Hökfelt, T. 2001. Hypothalamic and vagal neuropeptide circuitries regulating food intake. Physiol. Behav. 74:669-682.

4. Palkovits, M., Kiss, J.Z., Beinfeld, M.C., and Williams, T.H. 1982. Cholecystokinin in the nucleus of the solitary tract of the rat: evidence for its vagal origin. Brain Res. 252:386-390.

5. Luckman, S.M. 1992. Fos-like immunoreactivity in the brainstem of the rat following peripheral administration of cholecystokinin. J. Neuroendocrinol. 4:149-152.

6. Chen, C., Dun, S.L., Dun, N.J., and Chang, J.K. 1999. Prolactin-releasing peptide-immunoreactivity in $\mathrm{A} 1$ and $\mathrm{A} 2$ noradrenergic neurons of the rat medulla. Brain Res. 822:276-279.

7. Hinuma, S., et al. 1998. A prolactin-releasing peptide in the brain. Nature. 393:272-276.

8. Maruyama, M., et al. 1999. Immunocytochemical localization of prolactin-releasing peptide in the rat brain. Endocrinology. 140:2326-2333.

9. Ibata, Y., et al. 2000. Morphological survey of prolactin-releasing peptide and its receptor with special reference to their functional roles in the brain. Newrosci. Res. 38:223-230.

10. Lawrence, C.B., Celsi, F., Brennand, J., and Luckman, S.M. 2000. Alternative role for prolactinreleasing peptide in the regulation of food intake. Nat. Neurosci. 3:645-646.

11. Lawrence, C.B., Ellacott, K.L., and Luckman, S.M. 2002. PRL-releasing peptide reduces food intake and may mediate satiety signaling. Endocrinology. 143:360-367.

12. Ellacott, K.L., Lawrence, C.B., Rothwell, N.J., and Luckman, S.M. 2002. PRL-releasing peptide interacts with leptin to reduce food intake and body weight. Endocrinology. 143:368-374.

13. Lawrence, C.B., Liu, Y.L., Stock, M.J., and Luckman, S.M. 2004. Anorectic actions of prolactin-releasing peptide are mediated by corticotropin-releasing hormone receptors. Am. J. Physiol. Regul. Integr. Comp. Physiol. 286:R101-R107.

14. Ellacott, K.L., Lawrence, C.B., Pritchard, L.E., and Luckman, S.M. 2003. Repeated administration of the anorectic factor prolactin-releasing peptide leads to tolerance to its effects on energy homeostasis. Am. J. Physiol. Regul. Integr. Comp. Physiol. 285:R1005-R1010.

15. Bjursell, M., Lennerås, M., Göransson, M., Elmgren, A., and Bohlooly-Y, M. 2007. GPR10 deficiency in mice results in altered energy expenditure and obe- sity. Biochem. Biophys. Res. Commun. 363:633-638.

16. Maruyama, M., et al. 2001. Prolactin-releasing peptide as a novel stress mediator in the central nervous system. Endocrinology. 142:2032-2038.

17. Matsumoto, H., et al. 2000. Stimulation of corticotropin-releasing hormone-mediated adrenocorticotropin secretion by central administration of prolactin-releasing peptide in rats. Neurosci. Lett. 285:234-238.

18. Morales, T., and Sawchenko, P.E. 2003. Brainstem prolactin-releasing peptide neurons are sensitive to stress and lactation. Neuroscience. 121:771-778.

19. Zhu, L.L., and Onaka, T. 2003. Facilitative role of prolactin-releasing peptide neurons in oxytocin cell activation after conditioned-fear stimuli. Neuroscience. 118:1045-1053.

20. Laurent, P., et al. 2005. The prolactin-releasing peptide antagonizes the opioid system through its receptor GPR10. Nat. Neurosci. 8:1735-1741.

21. Gu, W., Geddes, B.J., Zhang, C., Foley, K.P., and Stricker-Krongrad, A. 2004. The prolactin-releasing peptide receptor (GPR10) regulates body weight homeostasis in mice. J. Mol. Neurosi. 22:93-103.

22. Bechtold, D.A., and Luckman, S.M. 2006. Prolactinreleasing Peptide mediates cholecystokinin-induced satiety in mice. Endocrinology. 147:4723-4729.

23. Bi, S., Scott, K.A., Kopin, A.S., and Moran, T.H. 2004. Differential roles for cholecystokinin a receptors in energy balance in rats and mice. Endocrinology. 145:3873-3880.

24. Bechtold, D.A., and Luckman, S.M. 2007. The role of RFamide peptides in feeding. J. Endocrinol. 192:3-15.

25. Fukusumi, S., Fujii, R., and Hinuma, S. 2006. Recent advances in mammalian RFamide peptides: the discovery and functional analyses of PrRP, RFRPs and QRFP. Peptides. 27:1073-1086.

26. Ohiwa, N., et al. 2007. Possible inhibitory role of prolactin-releasing peptide for ACTH release associated with running stress. Am. J. Physiol. Regul. Integr. Comp. Physiol. 292:R497-R504.

27. Onaka, T. 2004. Neural pathways controlling central and peripheral oxytocin release during stress. J. Neuroendocrinol. 16:308-312.

28. Fraser, K.A., and Davison, J.S. 1993. Meal-induced c-fos expression in brain stem is not dependent on cholecystokinin release. Am. J. Physiol. 265:R235-R239.

29. Rinaman, L., Baker, E.A., Hoffman, G.E., Stricker, E.M., and Verbalis, J.G. 1998. Medullary c-Fos activation in rats after ingestion of a satiating meal. Am. J. Physiol. 275:R262-R268.

30. Johnstone, L.E., Fong, T.M., and Leng, G. 2006. Neuronal activation in the hypothalamus and brainstem during feeding in rats. Cell Metab. 4:313-321.

31. Rinaman, L. 2003. Hindbrain noradrenergic lesions attenuate anorexia and alter central cFos expression in rats after gastric viscerosensory stimulation. J. Neurosci. 23:10084-10092.

32. Onaka, T., Luckman, S.M., Antonijevic, I., Palmer, J.R., and Leng, G. 1995. Involvement of the noradrenergic afferents from the nucleus tractus solitarii to the supraoptic nucleus in oxytocin release after peripheral cholecystokinin octapeptide in the rat. Neuroscience. 66:403-412.

33. Grabauskas, G., et al. 2004. Prolactin-releasing peptide affects gastric motor function in rat by modulating synaptic transmission in the dorsal vagal complex. J. Physiol. 561:821-839.

34. Hübschle, T., et al. 2001. Leptin-induced nuclear translocation of STAT3 immunoreactivity in hypothalamic nuclei involved in body weight regulation. J. Neurosci. 21:2413-2424.

35. Huo, L., Maeng, L., Bjørbaek, C., and Grill, H.J. 2007. Leptin and the control of food intake: neurons in the nucleus of the solitary tract are activated by both gastric distension and leptin. Endocrinology. 148:2189-2197.

36. Mera, T., et al. 2007. Downregulation of prolactinreleasing peptide gene expression in the hypothalamus and brainstem of diabetic rats. Peptides. 28:1596-1604.

37. Mera, T., et al. 2006. Prolactin-releasing peptide is a potent mediator of stress responses in the brain through the hypothalamic paraventricular nucleus. Neuroscience. 141:1069-1086.

38. Engström, M., Brandt, A., Wurster, S., Savola, J.M., and Panula, P. 2003. Prolactin releasing peptide has high affinity and efficacy at neuropeptide FF2 receptors. J. Pharmacol. Exp. Ther. 305:825-832.

39. Ellacott, K.L., et al. 2005. Characterization of a naturally-occurring polymorphism in the UHR-1 gene encoding the putative rat prolactin-releasing peptide receptor. Peptides. 26:675-681.

40. Kawakami, K., Onaka, T., Iwase, M., Homma, I., and Ikeda, K. 2005. Hyperphagia and obesity in $\mathrm{Na}, \mathrm{K}$-ATPase alpha2 subunit-defective mice. Obes. Res. 13:1661-1671.

41. Hashimoto, H., et al. 2007. Parathyroid hormonerelated protein induces cachectic syndromes without directly modulating the expression of hypothalamic feeding-regulating peptides. Clin. Cancer Res. 13:292-298.

42. Yamamoto, Y., Ueta, Y., Yamashita, H., Asayama, K., and Shirahata, A. 2002. Expressions of the preproorexin and orexin type 2 receptor genes in obese rat. Peptides. 23:1689-1696.

43. Nomura, M., et al. 2003. Enhanced up-regulation of corticotropin-releasing hormone gene expression in response to restraint stress in the hypothalamic paraventricular nucleus of oxytocin gene-deficient male mice. J. Neuroendocrinol. 15:1054-1061. 